\title{
¿PUTAS? QUIZÁS, ¿TONTITAS? JAMÁS: ANÁLISIS TRANSMEDIAL DE LA PARTICIPACIÓN POLÍTICA DE LAS MUJERES EN EL MOVIMIENTO ESTUDIANTIL CHILENO
}

\author{
(Whores? Maybe, Silly? Never: \\ Transmedial analysis of women' political participation on the Chilean student movement) \\ Camila Cárdenas ${ }^{1}$ \\ Carmen Cares $^{2}$
}

\begin{abstract}
We study how the participation of women is represented in the Chilean student movement, from the 2012 news coverage which catalogued the occupation of Internado Nacional Femenino de Nuñoa [National Boarding of Ñuño] as a "whorehouse". We rely on systemic-functional grammar (Halliday and Matthiessen, 2014) and the grammar of visual design (KRESS; van LEEUWEN, 2006) to analyze the ideational, interpersonal and textual meanings built in the corpus of study, consisting of the press releases that mediate the event as well as the images of protests occurring. We conclude that this polemic is an exemplary case of transmedia expansion, from which young people tension the hegemonic representations and their criteria of inequality, exclusion and marginalization. With that, students facilitate ideological reorientation, reframing their political and gender identities for the purpose of a legitimate claim.
\end{abstract}

Key words: Student Protest. Young Women. Gender. Discourse. Transmedial Analysis.

\section{RESUMEN}

Estudiamos cómo es representada la participación de las mujeres en el movimiento estudiantil chileno, a partir de la cobertura noticiosa que el año 2012 cataloga la ocupación del Internado Nacional Femenino de Ñuño como un "puterio". Nos basamos en la gramática sistémico funcional (Halliday y Matthiessen, 2014) y en la gramática del diseño visual (KRESS; van LEEUWEN, 2006) para analizar los significados ideacionales, interpersonales y textuales construidos en el corpus de estudio, compuesto por las noticias que mediatizan el evento y las imágenes de las protestas que le suceden. Concluimos que esta polémica constituye un caso ejemplar de expansión transmedia, a partir de la cual las jóvenes tensionan las representaciones hegemónicas y sus criterios de desigualdad, exclusión y marginación. Con ello las estudiantes favorecen la reorientación sociocognitiva, reenmarcando sus identidades políticas y de género con miras a una reivindicación legítima.

Palabras clave: Protesta Estudiantil. Mujeres Jóvenes. Género. Discurso. Análisis Transmedial.

\section{INTRODUCCIÓN}

El 10 de enero de 2012 el Alcalde de Ñuñoa ${ }^{3}$, Pedro Sabat, expresaba en el programa "Palabras sacan palabras" de Radio Futuro que "el Internado Nacional Femenino en toma era un

1 Estudiante del Doctorado en Traducción y Ciencias del Lenguaje de la Universitat Pompeu Fabra (Barcelona, España) y becaria del programa Becas Chile de la Comisión Nacional de Investigación Científica y Tecnológica (CONICYT). Correo electrónico: camila.cardenas.neira@gmail.com

2 Estudiante del Doctorado en Artes y Educación de la Universitat de Barcelona (Barcelona, España) y becaria del programa Becas Chile de la Comisión Nacional de Investigación Científica y Tecnológica (CONICYT). Correo electrónico: carmencares@gmail.com 
puterío", aludiendo a la ocupación que mantuvieron las jóvenes durante las movilizaciones estudiantiles ocurridas en Chile durante el 2011. Al ser apelado a retractar sus declaraciones por parte de Camila Vallejo, entonces vice-presidenta de la Federación de Estudiantes de la Universidad de Chile (FECH), Sabat insistió en su versión de los hechos, reforzando y endureciendo las descalificaciones en contra de las estudiantes, cuestión que rápidamente repercutió tanto en los medios de comunicación como en la opinión ciudadana.

Esta coyuntura nos llevó a preguntarnos ¿cómo fue representada la participación de las mujeres en las noticias que informaron sobre este evento y en las fotografías de las manifestaciones que le sucedieron? Guiadas por esta interrogante, nos planteamos tres objetivos de análisis: a) identificar y describir los textos primarios que difundieron las denominaciones con las cuales se asoció la acción política de las estudiantes con un "puterío"; 2) identificar y describir los textos secundarios con los cuales las estudiantes recontextualizaron las denominaciones asignadas, y; 3) explicar cómo los textos secundarios reconstruyeron estos significados a distintos niveles de realización semiótica.

Consideramos dos razones centrales que justifican la elección de este caso de estudio. En primer lugar, notamos que las jóvenes chilenas han adquirido un rol destacado en las vocerías y las dirigencias de diversas organizaciones secundarias y universitarias, y si bien se han investigado determinados procedimientos lingüísticos y visuales que facilitan la criminalización estudiantil (MONTECINO, 2011; PÉREZ, 2012, en prensa; Arancibia, Sadlier y Montecino, 2015), a la fecha no conocemos análisis que exploren cómo son construidas las identidades de género dentro de este movimiento. A su vez, se ha constatado que la adjudicación de toda clase de juicios y represalias que afectan a las $-\mathrm{y}$ los jóvenes se ha vuelto reiterativa en los últimos años de protestas sociales, sin que exista aún un adecuado tratamiento de estos casos de vulneración y vejación simbólica y material.

En segundo lugar, advertimos que la representación de las mujeres en los medios de comunicación de masas ha sido una preocupación constante para las estudiosas feministas, en tanto la producción de discursos sobre la "vida privada" contrasta con los "medios de información general" que refieren mayormente a la "vida pública" (FONTCUBERTA, 1994). Es

3 Ñuñoa es una comuna ubicada en el sector nororiente de la ciudad de Santiago, capital de Chile.

4 Se puede acceder a la grabación en: 〈https://goo.gl/3AQoLn>. 
en ese sentido que podemos sostener que los medios no necesariamente recluyen a las mujeres en los espacios domésticos, pero sí, muchos de ellos, establecen patrones diferenciados en virtud de los cuales se expone su intimidad negando la existencia de una vida personal autónoma, lo cual desvaloriza su participación pública sobre la base del control moral de sus acciones.

Nuestra propuesta de investigación se circunscribe en el campo de los Estudios Críticos del Discurso (ECD), enfoque multidisciplinar desde el cual nos aproximamos a la representación transmediática de las estudiantes movilizadas para dilucidar los ejercicios de poder y de resistencia que intervienen en la resignificación de las denominaciones que se les confieren. Teóricamente, abordamos el posicionamiento de las mujeres en el espacio político-social (HARAWAY, 1995; BRAIDOTTI, 2004; BUTLER, 2007) articulando las nociones de discurso y género (BUTLER, 2002; JULIANO, 2012; WODAK, 2015). Metodológicamente, sugerimos un modelo que combina análisis lingüístico desde una perspectiva sistémico-funcional (HALLIDAY; MATTHIESSEN, 2014), y análisis multimodal (KRESS; van LEEUWEN, 2006; van LEEUWEN, 2008; KRESS, 2010) y transmedial (LEMKE, 2003, 2009a, 2009b, 2013) desde una perspectiva socio-semiótica.

Nuestra hipótesis consiste en que, a partir del aprendizaje adquirido en los últimos ciclos de movilizaciones estudiantiles (2006-2015), las jóvenes chilenas cuestionan, cada vez más sistemáticamente, las prácticas hegemónicas que manipulan su visibilización pública, específicamente, los mecanismos de estereotipización que ponen a disposición múltiples etiquetas basadas en prejuicios machistas y adultocentristas, con las cuales se definen unilateralmente sus maneras de ser y de actuar. Para confrontar estas formas de dominación, y bajo unas condiciones de escenificación particulares, ellas despliegan un conjunto de estrategias comunicativas y políticas con el objetivo de desestabilizar los imperativos androcéntricos de control y abuso, tensionando las categorías que les competen y haciéndolas entrar en crisis. El análisis propuesto busca demostrar, en el caso escogido, cómo se llevan a cabo dichos procesos conjuntamente.

\section{FUndaMentación TEÓRICA}

La fundamentación teórica involucra la presentación y la discusión de las categorías en tensión, así como la oposición dialógica entre redes de resistencia y resignificación. 


\subsection{Denominación y poder: las categorías en tensión}

El acto de nombrar tiene implicancias teóricas y políticas que generan distinciones ontológicas profundas, las cuales afectan las disposiciones culturales y las formas de representación asociadas pues conllevan efectos sobre la construcción del conocimiento y la identidad (KRESS, 2010). Nombrar y nombrarse constituyen ejercicios diferenciados de poder, sobre los cuales los movimientos sociales de las últimas décadas -ligados a procesos migratorios, clases económicas, etnia o identidad sexual- han incidido a la hora de disputar las nominaciones ofensivas y contrarrestar su capacidad de exclusión (EMA LÓPEZ, 2004).

Por un lado, la categoría "mujer" se ha configurado históricamente desde la carencia, definiéndose en relación con lo que no se tiene según lo establecido, normado o valorado (PUJAL, 1993). Esta privación subyace a la especulación de una sociedad formada en una dicotomía antagónica no ambivalente, en donde mujeres y hombres están determinadas(os) por conductas que les son propias e impropias, atribuyéndoseles roles sociales conforme a su identificación biológica (DE BARBIERI, 1993; HARAWAY, 1995; TUBERT, 2003). Por ello el feminismo ha partido resignificando dicha categoría, proporcionando una teoría de género que explica la vinculación de los roles sociales con la construcción de la diferencia sexual (MONTECINO, 1997; LAGARDE, 2001; SCOTT, 2008).

Por otro lado, con la categoría "puta" se ha colectivizado a las mujeres bajo el dominio sexual de los hombres, congruentemente con la determinación biológica predominante que confiere una menor autonomía al cuerpo femenino en virtud de su capacidad reproductora. Esto explicaría por qué en el imaginario masculino todas las mujeres pueden ser putas (Juliano, 2004), independiente de si existe o no una transacción económica explícita que avale esta atribución.

El concepto de omisión (GALINDO; SÁNCHEZ, 2007) es útil para explicar por qué la puta está siempre ausente e invisibilizada públicamente, es expulsada de los espacios sociales y es rechazada como sujeto de derechos. Por ello apropiarse de esta negación, que oculta la remoción de todas las mujeres de los lugares que son conferidos tradicionalmente a los hombres, abre paso a la resistencia política. Porque su aparición en la esfera pública pone de manifiesto la existencia de un poder fáctico que oculta a las mujeres bajo la supremacía de lo masculino. 
Si los discursos construyen sujetos provistos o desprovistos de agencia -lo que se refleja oportunistamente en la representación política, social y jurídica de las mujeres (BUTLER, 2007)-, éstos también pueden prestarse para la acción contrahegemónica, pues la resignificación permite reconvertir la denominación en favor de la disidencia. Asumirse como putas es reconocerse con capacidad de actuación dentro de un contexto que nos identifica a todas como tales, lo cual no significa obviar los riesgos que implicam la naturalización de la prostitución y la suposición de que todo lo que se le asocia es normal y consentido (DE MIGUEL; TORRADO, 2014).

Ocupar la denominación y transformarla en una marca de identidad equivale a confrontar la doble moral que acusa a las mujeres, condena su libertad sexual y oculta voluntaria y convenientemente a los hombres de la práctica de la prostitución (DE MIGUEL, 2014); es invertir la estrategia hegemónica para el propio beneficio; restituir la visibilidad de las mujeres con la fuerza de una designación que no contempla al padre castrador ni a la pareja abusiva. Si todas las mujeres somos putas no existe el sentido de pertenencia como hijas, esposas o madres; no existe la figura masculina como símbolo del control y del dominio patriarcal. Y, por tanto, desaparece la afirmación de "que el padre, el marido, el patrón, el adulto, el profesor, «representa» un poder de Estado, el cual, a su vez, «representa» los intereses de una clase" (FOUCAULT, 1979, p.157).

La aparente ingenuidad con que la cultura popular diferencia la palabra de la imagen (KRESS, 2000) colabora para que esta última pueda enmascarar los discursos de discriminación, contribuyendo a la mantención de los estereotipos (van LEEUWEN, 2008). Por ello la relación entre cuerpo, imagen y representación visual es siempre conflictiva, porque a pesar de que la imagen provee a las mujeres de una representación asible, sus cuerpos han sido utilizados hasta lo insospechado por los determinismos de las ciencias biológicas y sociales positivistas, que esas mismas imágenes ayudan a modelar y perpetuar. No es de extrañar, entonces, que las jóvenes sean consideradas "putas", porque sus representaciones continúan sostenidas mayoritariamente en las decimonónicas nociones emparentadas con el uso de los cuerpos femeninos como objetos sexuales.

Es por ello que el cuerpo de las mujeres ha sido un campo de batalla decisivo (HARAWAY, 1995; BRAIDOTTI, 2004), ya que simboliza la crisis de una representación visual relativamente estable que otorga criterios predominantes de identificación social. Esto ha sido 
abiertamente cuestionado desde la teoría queer (BUTLER, 2002; PRECIADO, 2002), con la cual se problematiza la imbricación confusa entre sexo y género, pero sobre todo la articulación entre cuerpo, sexo y sexualidad. A pesar de ello, el uso estratégico de las imágenes puede aportar a la construcción de discursos de resistencia cuando se friccionan las bases que sustentan la naturalización de lo femenino, porque hace más patente que la pertenencia a un género no es un hecho claro sino un acto performático (WODAK, 2015).

La centralidad que las imágenes adquieren en la construcción de la identidad sexual radica en el efecto prototípico que estas causan (SERRANO et. al., 2011), así como en el rol que desempeñan para enmarcar la experiencia, "produciendo y haciendo cumplir de una forma selectiva lo que se contará como realidad" (BUTLER, 2011, p. 15). Cuando se toman decisiones sobre la semiosis, esto es, sobre la construcción de significados en formas modales, discursivas y genéricas (KRESS, 2010), es imprescindible considerar en qué medida la comunicación interviene en la representación de los géneros, enmarcando "lo que se quiere ver, lo que se sabe ver y aquello que se ve sin saber y sin querer" (SCHNAITH, 2011, p. 48, cursiva en el original).

La representación visual revela, en síntesis, motivaciones y efectos que son tanto sociales, culturales, como ideológicos (CÁRDENAS, 2014a), los cuales están condicionados por el poder de distintas maneras (van LEEUWEN, 2008), en lo que respecta, por ejemplo, a la inscripción de la autoría, la manipulación de los registros de visualización y visibilidad, la promoción de representaciones sociales que las imágenes negocian en diversos contextos de producción y circulación, los medios que privilegian o desestabilizan cierto estatuto epistémico de lo visual, entre otras variables. De esto deriva la necesidad de observar cómo el uso, la recontextualización y la distribución transmediática de estas imágenes reproduce, crea o modifica órdenes de sentido "que pueden contribuir a reforzar las relaciones de poder estructuradas y estabilizadas en la sociedad o que, por el contrario, pueden desafiar el dominio de los actores sociales hegemónicos" (PARDO, 2012, p. 49).

\subsection{Oposición dialógica: redes de resistencia y resignificación}

Los movimientos juveniles han demostrado una utilización cada vez más creciente de variados recursos lingüístico-semióticos que apropian en sus acciones colectivas (CÁRDENAS, 
2014a). La atención sobre los problemas socio-políticos que les competen, y el compromiso con ellos mediante prácticas contra-hegemónicas transformadoras, "rehace constantemente dichos recursos, y con ello, cambian su potencial para la acción futura en y sobre el mundo" (KRESS, 2010, p. 14). Desde esta manera, los y las jóvenes se convierten en diseñadoras(es) y, en palabras de Pardo (2012), mediadoras(es) de conocimiento, pues se abocan a re-mediar y re-presentar los aspectos de la sociedad que les resultan críticos, de acuerdo con las posibilidades modales de significación que tienen a su disposición (CÁRDENAS, 2014a).

La especificidad de las recientes movilizaciones estudiantiles radica en la profundización, la innovación y la complejización de los repertorios de acción e interacción comunicativa soportados tecnológicamente, lo que otorga a la internet y las redes sociales un rol destacado en la producción y la difusión de contradiscursos que cuestionan las representaciones adultocéntricas dominantes (CÁRDENAS, 2014b). En este contexto, es necesario comprender los ejercicios de resignificación que los y las estudiantes despliegan en el espacio público, a partir del trabajo simbólico que efectúan para resistir, tensionar e impugnar las etiquetas con las cuales se deslegitima su participación (CÁRDENAS, 2014c).

Cuando estos enfrentamientos de poder se expanden a la Web Social, es posible acceder a las voces disidentes presentes en los textos que se elaboran y difunden colaborativamente, los cuales amplifican las oportunidades de incidencia política en virtud de una estrategia de movilización transmedia (COSTANZA-CHOCK, 2010, 2012, 2013, 2014), que equivale a ocupar un conjunto de plataformas y recursos digitales para emplazar las protestas y las demandas que les subyacen. De este modo, los movimientos sociales desarrollan un conjunto de herramientas, habilidades, actividades y normas que los miembros emplean para crear, gestionar y extender sus formas de comunicación grupal (COSTANZA-CHOCK, 2012), con lo cual aspiran a "fortalecer la identidad colectiva, conseguir victorias culturales, políticas y económicas, y transformar la conciencia" (COSTANZA-CHOCK, 2013, p. 100).

En esta dirección, tomamos de Lemke (2003, 2009a, 2013) la noción de recorridos transmedia (transmedia traversals) para dar cuenta de los procesos semióticos que caracterizan la comunicación online de los movimientos juveniles, los cuales, según el autor, se expresan como redes intertextuales regidas por un principio de trans-contextualización, en virtud del cual cruzan las fronteras de los géneros y los medios, las comunidades y las instituciones. Dichos recorridos 
tienen la capacidad de articular y acumular significados a partir de la producción de ciertas cadenas semánticas hipermodales, las cuales orientan la interpretación discursiva a distintas escalas espaciales y temporales (LEMKE, 2009b), puesto que ayudarían a explicar "cómo y por qué los significados que hacemos aquí y ahora están conectados a los realizados por otros con los que formamos una red de interdependencia mutua" (LEMKE, 2001, p. 80).

Una de las características sobresalientes de estos recorridos transmedia es su apertura creativa, pues los y las usuarias(os) de la Web Social pueden generar y expandir los contenidos que les parecen relevantes de maneras infinitas, especialmente cuando éstos entran en contradicción con aquellos difundidos por los medios de comunicación tradicionales (CÁRDENAS, 2014c). De esa forma, este potencial productivo e interpretativo "tiende a asegurar que pocas de las naturalizaciones incrustadas por los poderes hegemónicos permanezcan intactas" (LEMKE, 2009a, p. 593), permitiendo "escapar del monologismo mediante la inclusión de múltiples voces sociales, lo que da a los(as) lectores(as) acceso al campo de la heteroglosia, a la diversidad de discursos y al conflicto" (LEMKE, 2003, p. 323).

Con ello se activa un tipo de oposición dialógica (LEMKE, 2003) que se basa en dos principios interrelacionados: el de resemiotización (IEDEMA, 2003), que considera la modificación de ciertos significados cuando éstos se desplazan de unos contextos mediáticos a otros, y el de intertextualidad (LEHTONEN, 2000), que supone la existencia de dos tipos de textos: primarios, los cuales aportan sentidos provenientes de un medio de origen, y secundarios, los cuales se derivan de otros medios cuyos sentidos refieren explícita o implícita a los primeros. Su correlación permite extraer, enlazar y negociar el conocimiento aportado por ambos textos conjuntamente, activando, en la mayoría de los casos, narraciones que estimulan los sentidos de pertenencia y afiliación, modulando creencias y emociones que soportan el enfrentamiento ideológico (CÁRDENAS, en revisión).

\section{Metodología}

\subsection{Conformación del corpus de estudio}

El corpus se obtuvo a partir de dos procedimientos. Primero buscamos en Google Web las noticias que se refirieran al evento mediático de nuestro interés, utilizando las siguientes 26 
combinaciones de palabras clave 5 : "movimiento + estudiantes + / puterío / putas / maracas" y "estudiantes + tomas $+/$ puterío / putas / maracas". Este procedimiento nos arrojó 15 noticias temáticamente pertinentes, de las cuales seleccionamos sólo aquellas que incluyeran declaraciones comunes, acotando la muestra a 8 textos primarios.

Luego replicamos la misma búsqueda en Google Imágenes. Este procedimiento nos arrojó 53 fotografías temáticamente pertinentes, de las cuales seleccionamos sólo aquellas que incluyeran referentes o símbolos comunes, acotando la muestra a 12 textos secundarios. De los 20 textos finales, en este artículo consideramos 4 primarios y 4 secundarios para ejemplificar el análisis.

\subsection{Modelo de análisis}

El modelo utilizado se basa en las aportaciones de la Lingüística Sistémico Funcional (LSF), específicamente, en la propuesta de las metafunciones del lenguaje (HALLIDAY; MATTHIESSEN, 2014), las cuales se asocian con: 1) la experiencia humana del mundo (significado ideacional), 2) los intercambios entre los participantes de la comunicación (significado interpersonal) y 3) la organización de cierta cantidad de información (significado textual). Dicha propuesta se circunscribe inicialmente al modo verbal, pero a corto andar es trasladada al modo visual por Kress y van Leeuwen (2006), quienes desarrollan una gramática del diseño visual que atiende: la configuración de los participantes y sus acciones (significado representacional), la relación entre los participantes representados y el observador (significado interactivo), y la disposición de los componentes de la imagen (significado composicional).

De esta ampliación se derivan importantes desarrollos teórico-metodológicos que, con el paso del tiempo, apuntan al cruce de los Estudios Críticos del Discurso (ECD) y los Estudios del Discurso Multimodal (EDM) (PARDO, 2012). Con este enfoque se abordan aquellos discursos públicos que recuperan problemáticas concretas de dominación o resistencia, y que se caracterizan por emplear, a lo menos, dos modos semióticos en combinación. Desde esta perspectiva, el análisis debe abordar la forma a partir de la cual estas modalidades se correlacionan funcionalmente, para producir sentido y orientar los procesos de producción y

\footnotetext{
5 Putas y maracas son variantes más coloquiales y vulgares de "prostitutas”.
} 
comprensión (PARDO, 2012), en virtud de los cuales se materializan y recuperan los intereses de los hacedores de signos (KRESS, 2010). Adicionalmente, debe considerarse cómo las actuales tecnologías afectan la semiosis, sobre todo cuando la construcción de sentido se desplaza de unos medios a otros (LEMKE, 2013).

Nuestra propuesta recoge estas aportaciones y se organiza en dos direcciones. Por un lado, analizamos los textos primarios empleando algunos elementos de los sistemas de transitividad, modo y temático, y reparamos en la relación intermodal entre el contenido y la imagen de las noticias. Por otro lado, analizamos los textos secundarios atendiendo los significados representacionales, interactivos y composicionales construidos en las fotografías, y nos detenemos en las relaciones transmediales que se articulan entre ellas. En la Tabla 1 presentamos una síntesis de las categorías y los componentes correspondientes.

Tabla 1. Modelo de análisis

\begin{tabular}{|c|c|c|}
\hline \multicolumn{3}{|c|}{ TEXTOS PRIMARIOS } \\
\hline Significado ideacional & \multirow{2}{*}{$\begin{array}{l}\text { Significado interpersonal } \\
\text { SISTEMA DE MODO: finitos y } \\
\text { adjuntos }\end{array}$} & \multirow{2}{*}{$\frac{\text { Significado textual }}{\text { SISTEMA TEMÁTICO: tema y foco }}$} \\
\hline $\begin{array}{l}\text { SISTEMA DE } \\
\text { procesos y actores }\end{array}$ & & \\
\hline \multicolumn{3}{|c|}{$\begin{array}{l}\text { Relaciones intermodales: } \\
\text { entre el texto y la imagen de cada una de las noticias }\end{array}$} \\
\hline \multicolumn{3}{|c|}{ TEXTOS SECUNDARIOS } \\
\hline Significado representacional & Significado interactivo & Significado composicional \\
\hline CONFIGURACIÓN & RELACIÓN ENTRE LOS & ORGANIZACIÓN DE LOS ELEMENTOS DE \\
\hline $\begin{array}{l}\text { PARTICIPANTES Y SUS ACCIONES: } \\
\text { exclusión, } \\
\text { especificación o } \\
\begin{array}{l}\text { determinación, } \\
\text { individualización o } \\
\text { categorización }\end{array}\end{array}$ & $\begin{array}{ll}\text { PARTICIPANTES } & \text { Y EL } \\
\text { OBSERVADOR: } & \text { contacto, } \\
\text { distancia y actitud } & \end{array}$ & $\begin{array}{l}\text { LA IMAGEN: valor de la información, } \\
\text { prominencia y encuadre }\end{array}$ \\
\hline
\end{tabular}

\section{RESUltados}

La discusión de los resultados del estudio se encuentra en las dos sesiones presentadas abajo. 


\subsection{Textos Primarios (TP)}

Son aquellos que fijan y facilitan la circulación de las denominaciones en la esfera pública, y cumplen con el fin de hetero-representar negativamente a las jóvenes movilizadas. En la Tabla 2 desglosamos el análisis de los ejemplos.

Tabla 2. Síntesis del análisis de las noticias seleccionadas

\begin{tabular}{|c|c|c|c|}
\hline \multirow[t]{2}{*}{ ID } & S-ideacional & S-interpersonal & \multirow{2}{*}{$\begin{array}{l}\text { S-textual } \\
\text { Temático }\end{array}$} \\
\hline & Transitividad & Modo & \\
\hline $\mathrm{TP}^{-16}$ & $\begin{array}{l}\text { Se emplean mayoritariamente } \\
\text { procesos verbales para precisar } \\
\text { los dichos de Sabat, y algunos } \\
\text { procesos mentales para dar a } \\
\text { conocer sus estados de ánimo, } \\
\text { por lo que él es el principal } \\
\text { actor -emisor y sensor- del } \\
\text { discurso. }\end{array}$ & $\begin{array}{l}\text { El uso de finitos y adjuntos es } \\
\text { escaso y funciona, en general, } \\
\text { para introducir proposiciones } \\
\text { (declaraciones). Destacan } \\
\text { algunos adjuntos de frecuencia } \\
\text { (baja) para evaluar } \\
\text { negativamente las acciones de } \\
\text { sus opositores políticos, y de } \\
\text { disposición (habilidad) para } \\
\text { minimizar su comportamiento } \\
\text { improcedente. }\end{array}$ & $\begin{array}{l}\text { El alcalde es foco y tema } \\
\text { de los enunciados en casi } \\
\text { toda la noticia, salvo en } \\
\text { una ocasión donde aparece } \\
\text { el gobierno (de Piñera), al } \\
\text { que critica por su } \\
\text { incapacidad de resolver el } \\
\text { conflicto educativo. }\end{array}$ \\
\hline TP- $2^{7}$ & $\begin{array}{l}\text { Se combinan procesos } \\
\text { materiales, verbales y mentales } \\
\text { para dar cuenta de las acciones, } \\
\text { los dichos y los pensamientos } \\
\text { de Sabat, sin dar cabida a otros } \\
\text { participantes. }\end{array}$ & $\begin{array}{l}\text { Se emplean adjuntos modales } \\
\text { de frecuencia y polaridad } \\
\text { negativa para condenar la } \\
\text { reiteración de paros y } \\
\text { ocupaciones, y recalcar los } \\
\text { perjuicios que esto produce en } \\
\text { los/as estudiantes que no se } \\
\text { movilizan. }\end{array}$ & $\begin{array}{l}\text { Tanto Sabat como sus } \\
\text { declaraciones } \\
\text { constituyen en todos los } \\
\text { enunciados como el foco y } \\
\text { el tema de la noticia. }\end{array}$ \\
\hline TP- $3^{8}$ & 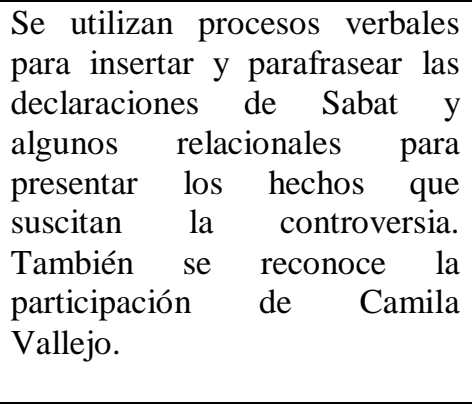 & $\begin{array}{l}\text { Sobresale el uso de adjuntos } \\
\text { modales de polaridad negativa } \\
\text { y de obligación para } \\
\text { desvincular a Sabat de los } \\
\text { despidos de profesores/as y las } \\
\text { expulsiones de alumnos/as, y } \\
\text { para subrayar los daños } \\
\text { materiales y educativos que } \\
\text { estas protestas acarrean a la } \\
\text { comuna y sus liceos. }\end{array}$ & $\begin{array}{l}\text { También es notorio que } \\
\text { Sabat y sus dichos } \\
\text { equiparan la posición } \\
\text { temática a lo largo de la } \\
\text { noticia, por lo que los } \\
\text { hechos que se exponen } \\
\text { como lo dado o conocido } \\
\text { se enfocan siempre desde } \\
\text { su punto de vista. }\end{array}$ \\
\hline TP-4 ${ }^{9}$ & $\begin{array}{l}\text { Se incluyen procesos verbales y } \\
\text { mentales para introducir los }\end{array}$ & $\begin{array}{lll}\text { Se emplean } & \text { sólo algunos } \\
\text { adjuntos de } & \text { frecuencia y }\end{array}$ & $\begin{array}{l}\text { Si bien también se repite la } \\
\text { disposición de Sabat y sus }\end{array}$ \\
\hline
\end{tabular}

${ }^{6}$ La Segunda, 11 de enero de 2012: http://goo.gl/GnTTiB

7 Soy Chile, 11 de enero de 2012: http://goo.gl/4gCPMh

${ }^{8}$ El Mostrador, 11 de enero de 2012: http://goo.gl/LXfaEr

${ }^{9}$ La Nación, 11 de enero de 2012: http://goo.gl/XdKvIG 


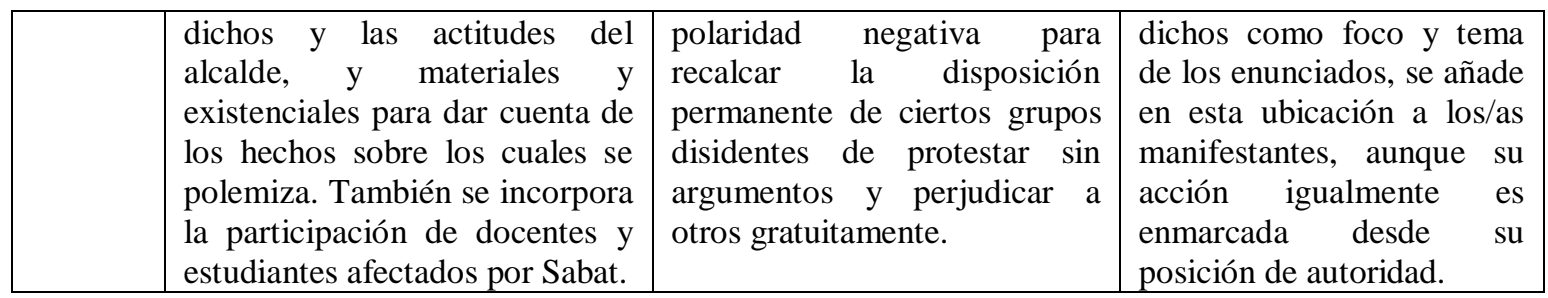

En términos generales, las noticias se configuran desde una perspectiva heteroglósica que recurre mayoritariamente a la inserción de citas directas, aunque en TP-1 y TP-3 se emplea la asimilación de citas indirectas en algunos pocos casos, de modo que los procesos y las agencias que adquieren preponderancia son aquellas que se enfocan desde la perspectiva del alcalde Sabat. Tales citas coinciden en los diarios explorados, salvo en TP-1, donde éstas son más extensas y variadas con el objetivo de precisar los dichos en favor del edil. TP-4 es el único medio que incorpora la participación de las manifestantes en posición temática, mientras que TP-1 lo hace en posición remática como complementos circunstanciales. Sin embargo, ningún ejemplo les otorga voz en el discurso.

Sólo TP-3 y TP-4 incluyen imágenes, y en ambos casos son fotografías del alcalde que representan atributos asociados con su poder político, su actitud enérgica, determinante y categórica. Con ello se obtiene una relación intermodal de contextualización, en virtud de la cual el modo visual proyecta y refuerza los significados construidos por el modo escrito, de manera que Sabat y sus juicios obtienen pleno protagonismo.

En síntesis, los textos primarios criminalizan a las jóvenes movilizadas en dos direcciones. Primero se condena que las estudiantes hayan admitido el ingreso de hombres al liceo y hayan convivido con sus parejas durante la ocupación. Luego se reprochan ciertas acciones como destruir mobiliario e intercambiar alcohol y drogas por favores sexuales. Lo anterior modela una representación mediática asentada en la desobediencia y la desviación moral, de modo que su participación política se banaliza y tergiversa trastocando sus derechos de ocupar libre y legítimamente sus espacios, así como disponer autónomamente de sus cuerpos, siendo objetos de censura y recriminación, todo lo cual se enmarca desde el poder adulto, masculino y conservador. 


\subsection{Textos Secundarios (TS)}

Son aquellos que subvierten las denominaciones de origen recontextualizándolas en la esfera pública, y cumplen con el fin de auto-representar positivamente a las jóvenes movilizadas. A continuación, desglosamos el análisis de los ejemplos.

Tabla 3. Síntesis del análisis del TS $-1^{10}$

\begin{tabular}{|c|c|c|}
\hline S-representacional & S-interactivo & S-composicional \\
\hline Participantes & Contacto & Valor de la información \\
\hline $\begin{array}{l}\text { - Grupo de mujeres jóvenes que } \\
\text { personifican el rol social de } \\
\text { prostitutas. } \\
\text { - Generalización y agrupación } \\
\text { como colectivo. } \\
\text { - Categorización por símbolos } \\
\text { culturales. }\end{array}$ & $\begin{array}{l}\text { - Se construye una demanda } \\
\text { hacia el observador, } \\
\text { instándolo a involucrarse en } \\
\text { las acciones representadas. }\end{array}$ & $\begin{array}{l}\text { - El eje conocido/nuevo coincide } \\
\text { con la disposición cromática } \\
\text { (colores cálidos/fríos) atribuida a la } \\
\text { distinción femenino/masculino. }\end{array}$ \\
\hline Acciones & Distancia & Prominencia \\
\hline \multirow{3}{*}{$\begin{array}{l}\text { - Performar, interpelar, } \\
\text { manifestarse. } \\
\text { - Resultan re-legitimadas a partir de } \\
\text { una re-evaluación moral que } \\
\text { subvierte la autoridad y los sistemas } \\
\text { de valores establecidos en una } \\
\text { sociedad patriarcal. }\end{array}$} & $\begin{array}{l}\text { - Es social y el ángulo de } \\
\text { captura de la imagen } \\
\text { proporciona detalles de los } \\
\text { elementos portados, fijando } \\
\text { la atención sobre ellos. }\end{array}$ & $\begin{array}{l}\text { - Las mujeres ocupan el primer y el } \\
\text { segundo plano de la imagen para } \\
\text { destacar sus posesiones (pancartas, } \\
\text { vestuario y accesorios). }\end{array}$ \\
\hline & Actitud & Encuadre \\
\hline & $\begin{array}{l}\text { - Propone una relación de } \\
\text { igualdad que } \\
\text { aceptación y y empone } \\
\text { respecto de las acciones } \\
\text { registradas. }\end{array}$ & $\begin{array}{l}\text { - Se enmarca a las tres mujeres, en } \\
\text { tanto colectivo representativo, de } \\
\text { modo de enfocar sus consignas y } \\
\text { dar realce a la personificación que } \\
\text { realizan como forma de protesta. }\end{array}$ \\
\hline
\end{tabular}

En TS-1 se registra una construcción estereotipada de las prostitutas, mediante posesiones y atributos asociados simbólicamente al ejercicio de este oficio: los accesorios y el vestuario llamativo y sensual. Se evoca la generalización y la agrupación de las mujeres que coordinan su acción colectiva, quienes, a su vez, performan este rol social para reconvertir el carácter negativo de la denominación, asumiendo el agravio como oportunidad de interpelación y reivindicación, pues se reapropia como una identidad que se expone con orgullo y dignidad. El mensaje portado ("me emputece") apela tanto al responsable de los dichos como a la sociedad en cuanto conjunto representativo de lo heteronormativo y de la violencia sistemática ejercida en contra de las mujeres.

10 Tía Zurda, 14 de enero de 2012: http://goo.gl/qEfrJG 
Tabla 4. Síntesis del análisis del TS-2 $2^{11}$

\begin{tabular}{|c|c|c|}
\hline S-representacional & S-interactivo & S-composicional \\
\hline Participantes & Contacto & Valor de la información \\
\hline $\begin{array}{l}\text { - Hombre adulto que asume el rol } \\
\text { social de padre. } \\
\text { - Aunque parece clara la } \\
\text { individualización, se presume que } \\
\text { el actor representa a un grupo más } \\
\text { amplio de padres cuyas hijas } \\
\text { fueron insultadas. }\end{array}$ & $\begin{array}{l}\text { - Se construye una oferta hacia el } \\
\text { observador, quien asume la } \\
\text { condición de testigo de las } \\
\text { acciones representadas. }\end{array}$ & $\begin{array}{l}\text { - Pese a que es notoria la } \\
\text { centralidad del participante, una } \\
\text { leve inclinación a la derecha y } \\
\text { abajo ubica su acción en el } \\
\text { plano conocido/real, } \\
\text { volviéndola de común acuerdo e } \\
\text { incuestionable. }\end{array}$ \\
\hline Acciones & istancia & Prominencia \\
\hline \multirow{3}{*}{$\begin{array}{l}\text { - Impugnar, insultar, manifestarse. } \\
\text { - Las acciones resultan re- } \\
\text { legitimadas mediante la } \\
\text { autorización personal y de rol } \\
\text { modelo, con lo cual se distingue } \\
\text { unas mujeres (hijas) de otras, } \\
\text { implicando que algunas de ellas } \\
\text { deben ser respetadas y otras no. }\end{array}$} & $\begin{array}{l}\text { - Es social y el ángulo de captura } \\
\text { de la imagen permite abarcar } \\
\text { completamente el mensaje que } \\
\text { presenta la impugnación. }\end{array}$ & $\begin{array}{l}\text { - La pancarta abarca el primer } \\
\text { plano de la imagen, destacando } \\
\text { la posición del manifestante y su } \\
\text { interpelación. }\end{array}$ \\
\hline & Actitud & Encuadre \\
\hline & $\begin{array}{l}\text { - Si bien se evoca algún grado de } \\
\text { igualdad, la dirección oblicua } \\
\text { establece cierta separación para } \\
\text { distinguir a los padres de las } \\
\text { hijas. }\end{array}$ & $\begin{array}{l}\text { - Se enmarca al actor para } \\
\text { diferenciar su rol social del resto } \\
\text { de los participantes en segundo } \\
\text { plano. }\end{array}$ \\
\hline
\end{tabular}

En TS-2 se destaca al padre protector y reaccionario que defiende la honra de su hija. Dicha identificación, no obstante, emplea un adjetivo posesivo por medio del cual se construye esta afiliación, uso que reafirma la identificación de las mujeres como propiedad de los hombres. El mensaje portado y la distinción realizada con los colores (“tu hija es di-puta-da la mía no") constituye un ataque indirecto a Sabat a través de su hija, dirigido más bien a su masculinidad patriarcal y no a su rol político. Así, no se reivindica el insulto a las mujeres en general sino sólo a las estudiantes afectadas por sus dichos.

Tabla 5. Síntesis del análisis del TS-3 $3^{12}$

\begin{tabular}{|c|c|c|}
\hline S-representacional & S-interactivo & S-composicional \\
\hline Participantes & Contacto & Valor de la información \\
\hline $\begin{array}{l}\text { - El monumento corresponde a un } \\
\text { prócer de patria: Bernardo O'Higgins. }\end{array}$ & 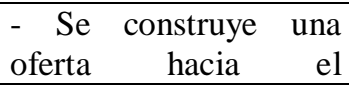 & $\begin{array}{l}\text { - La disposición oblicua ubica la } \\
\text { pancarta en el eje derecho/abajo de }\end{array}$ \\
\hline
\end{tabular}

\footnotetext{
${ }^{11}$ Urbanox, 13 de enero de 2012: http://goo.gl/T4dVXn

12 El mostrador, 14 de enero de 2012: http://goo.gl/TEUlQI 


\begin{tabular}{|c|c|c|}
\hline $\begin{array}{l}\text { - Es individualizado, pero se le atribuye } \\
\text { una identidad ('maraca') que lo } \\
\text { redefine, siendo la meta de la acción de } \\
\text { terceros. }\end{array}$ & $\begin{array}{l}\text { observador, quien } \\
\text { asume la condición de } \\
\text { testigo de las acciones } \\
\text { representadas. }\end{array}$ & $\begin{array}{l}\text { la imagen, esto es, lo conocido/real. } \\
\text { En el eje izquierdo/arriba se ubica el } \\
\text { monumento intervenido en el plano } \\
\text { nuevo/ideal. }\end{array}$ \\
\hline Acciones & Distancia & Prominencia \\
\hline \multirow[t]{3}{*}{$\begin{array}{l}\text { - Subvertir, atribuir, manifestarse. } \\
\text { - Las acciones resultan re-legitimadas } \\
\text { por la desobediencia a la autoridad } \\
\text { derivada de la tradición y la } \\
\text { racionalidad histórica (masculina y } \\
\text { adultocéntrica). }\end{array}$} & $\begin{array}{l}\text { - La distancia es } \\
\text { íntima, representa la } \\
\text { transgresión } \\
\text { espacio personal, en } \\
\text { este caso, heroico y } \\
\text { emblemático. }\end{array}$ & $\begin{array}{l}\text { - La dirección de lectura inicia con } \\
\text { la pancarta y finaliza con el } \\
\text { personaje histórico, por lo que es el } \\
\text { verbiaje adjudicado lo primero que } \\
\text { se destaca en la composición. }\end{array}$ \\
\hline & Actitud & Encuadre \\
\hline & $\begin{array}{l}\text { - Dado que el ángulo es } \\
\text { desde abajo se propone } \\
\text { una relación de poder } \\
\text { desde el participante } \\
\text { representado al } \\
\text { observador. }\end{array}$ & $\begin{array}{l}\text { - Ambos planos se conectan por el } \\
\text { vector que asocia el mensaje al } \\
\text { personaje que se le atribuye. }\end{array}$ \\
\hline
\end{tabular}

En TS-3 el diseño visual presenta un mensaje con el cual se designa al personaje histórico el rol de "maraca", cuya condición es reconvertida por un elemento simbólico: el sujetador que cuelga sobre sus ojos. Con esto se crea una distorsión en la construcción del héroe patrio marcada por la masculinización de sus atributos, la cual es subvertida con esta intervención satírica, resultando, entonces, feminizado. La pancarta incluye una interpelación al observador (“¿y qué?’), que alude a esta memoria histórica oficial y hegemónica tensionada y puesta en duda.

Tabla 6. Síntesis del análisis del TS-4 ${ }^{13}$

\begin{tabular}{|c|c|c|}
\hline S-representacional & S-interactivo & S-composicional \\
\hline Participantes & Contacto & Valor de la información \\
\hline $\begin{array}{l}\text { - Grupo de mujeres y hombres } \\
\text { jóvenes que personifican el rol } \\
\text { social de 'maracas'. } \\
\text { - Generalización y agrupación } \\
\text { como colectivo. } \\
\text {-Categorización por símbolos } \\
\text { culturales. }\end{array}$ & $\begin{array}{l}\text { - Dentro del grupo hay } \\
\text { participantes que establecen } \\
\text { contacto visual y otros que no, } \\
\text { por lo que se construye } \\
\text { simultáneamente una demanda } \\
\text { y una oferta al observador, } \\
\text { apelándolo como participante } \\
\text { y testigo. }\end{array}$ & $\begin{array}{l}\text { - El eje centro/periferia enfoca el } \\
\text { avance de los manifestantes, mientras } \\
\text { que el eje arriba/abajo enfatiza los } \\
\text { rasgos de masividad e identificación. }\end{array}$ \\
\hline Acciones & Distancia & Prominencia \\
\hline \multirow[t]{2}{*}{$\begin{array}{l}\text { - Identificarse, marchar, } \\
\text { manifestarse. } \\
\text { - Las acciones resultan re- } \\
\text { legitimadas a partir de una re- } \\
\text { evaluación moral que }\end{array}$} & $\begin{array}{l}\text { - La toma lejana construye } \\
\text { impersonalidad con el fin de } \\
\text { diferenciar a los manifestantes } \\
\text { de quienes no lo son. }\end{array}$ & $\begin{array}{l}\text { - El lienzo y el bloque de avanzada en } \\
\text { primer plano destacan la cohesión y la } \\
\text { convicción grupal que aúna la acción } \\
\text { de hombres y mujeres jóvenes. }\end{array}$ \\
\hline & Actitud & Encuadre \\
\hline
\end{tabular}

${ }^{13}$ El mostrador, 14 de enero de 2012: http://goo.gl/TEUlQI 


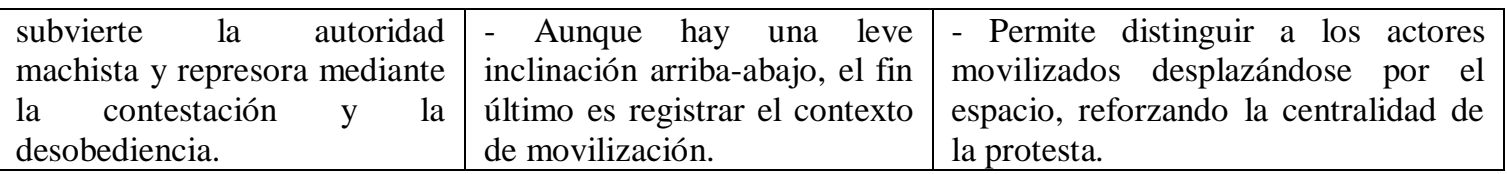

En TS-4 los y las jóvenes conforman un colectivo identificado como "las maracas". La acción grupal neutraliza la distinción por género, constituyéndose en una reivindicación generacional de mayor alcance. Destaca la predominancia simbólica del rojo como color asociado a la práctica de la prostitución, el que conecta semióticamente la denominación inscrita en el lienzo, el zapato de tacón y los labios de las estudiantes. Esta marca identitaria restituye un valor de lucha a un referente asociado culturalmente con la sexualidad como bien de intercambio, de manera que trasciende un tipo de dominio vinculado a unos roles específicos, y en su lugar afecta a hombres y mujeres jóvenes que se movilizan en conjunto, sin diferencias ni jerarquías predeterminadas.

En síntesis, los textos secundarios analizados cumplen con el objetivo de resignificar la denominación que se presume como ofensa, satisfaciendo tres funciones fundamentales que desarrollamos en la Tabla 7.

Tabla 7. Síntesis del análisis de los textos secundarios

\begin{tabular}{|c|c|c|}
\hline $\begin{array}{l}\text { ón } \\
\text { ición }\end{array}$ & $\begin{array}{r}T \\
\text { de lo } \\
\end{array}$ & $\begin{array}{r}\text { Reat } \\
\text { de la de }\end{array}$ \\
\hline $\begin{array}{l}\text { Marca de pertenencia grupal: el } \\
\text { rol social es performado para } \\
\text { delimitar la composición del } \\
\text { endogrupo, y extenderlo a hombres } \\
\text { y mujeres jóvenes. }\end{array}$ & $\begin{array}{l}\text { Distinción entre el exogrupo y el } \\
\text { endogrupo: "tu hija" versus "mi } \\
\text { hija", "nuestras mujeres" versus } \\
\text { "sus mujeres". }\end{array}$ & $\begin{array}{l}\text { Integración estratégica: se } \\
\text { atribuye } \text { la } r \text { misma } \\
\text { identificación a un referente } \\
\text { externo para reforzar la crítica } \\
\text { política. }\end{array}$ \\
\hline $\begin{array}{l}\text { Adjudicación positiva: la } \\
\text { identidad asignada deviene en un } \\
\text { recurso político que activa una } \\
\text { oposición concertada a los sistemas } \\
\text { de dominación impuestos. }\end{array}$ & $\begin{array}{l}\text { Adjudicación negativa: } \\
\text { carácter ofensivo asignado a la } \\
\text { denominación es validado si se } \\
\text { aplica a otra mujer para denostar } \\
\text { al adversario político. }\end{array}$ & $\begin{array}{l}\text { Exaltación paródica: se } \\
\text { desestabiliza una construcción } \\
\text { histórica que consolida la } \\
\text { estructura } \\
\text { reproductora de desigualdades } \\
\text { y abusos. }\end{array}$ \\
\hline $\begin{array}{l}\text { Mutación del estado a la acción: } \\
\text { "emputecerse" y "marchar" como } \\
\text { reacciones a la estereotipización de } \\
\text { género vinculada con la libertad de } \\
\text { la mujer y el ejercicio de su } \\
\text { autonomía en el espacio público. }\end{array}$ & $\begin{array}{l}\text { Mantención del estereotipo de } \\
\text { género: se consolida la } \\
\text { naturalización del rol en disputa } \\
\text { sin deconstruir las lógicas de } \\
\text { marginación y exclusión que } \\
\text { promueve. }\end{array}$ & $\begin{array}{l}\text { Transgresión de los roles de } \\
\text { género: se subvierten actitudes } \\
\text { y valores asociados a lo } \\
\text { femenino y lo masculino } \\
\text { mediante la transposición de } \\
\text { ciertas posesiones y cualidades. }\end{array}$ \\
\hline
\end{tabular}


Estas funciones posibilitan la subversión ideológica de la denominación y potencian su carácter como estrategia política de relegitimación. De esta forma, la correlación establecida entre los simbolismos compartidos, en los cuales reside justamente el carácter performativo de esta protesta estudiantil, muestra cómo se ponen en juego los significados en disputa, haciéndolos entrar en crisis. Con ello se reposiciona públicamente la participación de las mujeres que resisten sistemáticamente la imposición de autoridad, y se socavan los mandatos sociales que prescriben y naturalizan ciertos criterios de identificación juvenil que perviven como sistemas estables de poder.

\section{CONSIDERACIONES FinALES}

Creemos que la coyuntura mediática considerada desencadena un caso ejemplar de expansión transmedia, en razón de la cual las jóvenes confrontan los dispositivos hegemónicos que criminalizan su participación política, redefiniendo los criterios de desigualdad, exclusión y marginación que los fundamentan. Esta estrategia comunicativa favorece la reorientación sociocognitiva toda vez que trastoca los prejuicios machistas y adultocentristas de origen, de modo que las estudiantes reenmarcan sus identidades con miras a una reivindicación legítima de su acción colectiva.

Planteamos que el trabajo semiótico llevado a cabo por las jóvenes se orienta, a lo menos, en dos dimensiones: 1) el de recontextualización de los sentidos dominantes, que incluye la apropiación de las denominaciones que los textos primarios circunscriben en la esfera pública, su reutilización en textos secundarios que surgen en otras prácticas sociales, y la reconversión ideológica que supone dar un valor positivo a las etiquetas que en principio se emplean con efectos estereotipadores, y; 2) el de expansión de los sentidos resistentes, que incluye la amplificación de discursos de autoría juvenil en espacios de interacción offline y online, su articulación con otros discursos con los cuales comparten referentes o símbolos comunes, y la búsqueda de solidaridad ideológica entre los miembros que adhieren a las impugnaciones que dichos referentes o símbolos promueven.

De lo anterior deviene la transformación de las representaciones sociales en pugna, procedimiento meta-cognitivo en virtud del cual se resiste la hetero-representación negativa, 
redefiniendo dos criterios de identificación juvenil predominantes: el de género y el de generación. Así, la auto-representación positiva resulta de la espectacularización y la exaltación paródica de las características que son objeto de discriminación, de forma que esta oposición dialógica se distingue de otras tácticas de contención por afectar, precisamente, las prácticas de significación que la hacen posible.

Recebido em: março de 2016

Aprovado em: outubro de 2016 camila.cardenas.neira@gmail.com carmencares@gmail.com

\section{REFERENCIAS}

ARANCIBIA, C.; SADLIER, S.; MONTECINO, L. Impact of Social Media on Chilean Student Movement. In K. P. Kallio et al. (Eds.), Politics, Citizenship and Rights. Singapore: Springer, 2015. p. 331-344.

BRAIDOTTI, R. Feminismo, diferencia sexual y subjetividad nómade. Barcelona: Gedisa, 2004.

BUTLER, J. Violencia de estado, guerra, resistencia. Por una nueva política de la izquierda. Madrid: Katz, 2011. 2007.

El género en disputa. El feminismo y la subversión de la identidad. Barcelona: Paidós,

Cuerpos que importan. Sobre los límites materiales y discursivos del cuerpo. Barcelona:

Paidó, 2002.

CÁRDENAS, C. Representación visual de la movilización estudiantil en Chile: Las fotografías de las marchas como espacios de narración, actuación e identificación política. Revista Onomázein, 2014a. (Número Especial IX ASFAL), p.115-137.

Representación de la acción política de los estudiantes chilenos. Movilización de significados en redes sociales. Revista Última Década, 2014b. (40), p. 57-84.

Inútiles y subversivos: Representación transmedia de los estudiantes chilenos en redes sociales. Revista Romanica Olomucensia, 2014c. vol.26 (2),p. 173-190.

. (en revisión). El movimiento estudiantil chileno y la Web Social: Nuevos repertorios de acción e interacción comunicativa. Revista Psicoperspectivas. 
CONSTANZA-CHOCK, S. Out of the Shadows, Into the Streets! Transmedia Organizing and the Immigrant Rights Movement. Cambridge: MIT Press, 2014.

. Transmedia Mobilization in the Popular Association of the Oaxacan Peoples, Los Angeles. In B. Cammaerts, A. Mattoni y P. McCurdy (Eds.), Mediation and Protest Movements. Chicago: Intellect-The University of Chicago Press, 2013.p. 65-144.

. Mic Check! Media Cultures and the Occupy Movement. Social Movement Studies. 2012.En línea, disponible en: http://dx.doi.org/10.1080/14742837.2012.710746 (consultado el 3 de marzo de 2013).

Se ve, se siente: Transmedia Mobilization in the Los Angeles Immigrant Rights Movement. California: Faculty of the USC Graduate School, University of Southern California, 2010

DE BARBIERI, T. Sobre la categoría de género. Una introducción teórico metodológica. Debates en Sociología, 1993, (18), p.145-169.

DE FONTCUBERTA, M. Imagen, mujer y medios. En: VILANOVA, M. (Ed.), Pensar las diferencias. Barcelona: Seminario Interdisciplinar Mujeres y Sociedad, 1994, p.149-178.

DE MIGUEL, A. La prostitución de las mujeres, una escuela de desigualdad humana. Dilemata, Revista de Éticas Aplicadas, 1994, vol.6 (16), 7-30.

DE MIGUEL, A.; TORRADO, E. Introducción: Debates y dilemas en torno a la prostitución y la trata. Dilemata, Revista de Éticas Aplicadas,1994, vol.6 (16), 1-6.

EMA LÓPEZ, J. E. Del sujeto a la agencia (a través de lo político). Athenea Digital,2004, (6), 124.

FOUCAULT, M. Microfísica del poder. Madrid: Las Ediciones de la Piqueta, 1979

GALINDO, M. Y SÁNCHEZ, S. Ninguna mujer nace para puta. Buenos Aires: Lavaca, 2007.

HALLIDAY, M. A. K.; MATTHIESSEN, C. Halliday's Introduction to Functional Grammar. $4^{\text {th }}$ Ed. London-New York: Routledge, 2014.

HARAAY, D. Ciencia, cyborgs y mujeres. La reinvención de la naturaleza. Madrid: Cátedra, 1995.

IEDEMA, R. Multimodality, Resemiotization: Extending the Analysis of Discourse as MultiSemiotic Practice. Visual Communication, 2003. vol.2 (1), 29-57.

JULIANO, D. Excluidas y marginales: Una aproximación antropológica. Madrid: Cátedra, 2004. 
KRESS, G. Multimodality. A Social Semiotic Approach to Contemporary Communication. London-New York: Routledge, 2010.

KRESS, G.; VAN LEEUN, T. Reading Images. The Grammar of Visual Design. New York: Routledge, 2006.

LAGARDE, M. Género y feminismo. Madrid: Horas y Horas, 2001.

LETHONEN, M. On No Man's Land. Theses on Intermediality. Nordicom Information, 2000, (34): 11-24.

LEMKE, J. Multimedia and Discourse Analysis. In J. P. Gee y M. Handford (Eds.), Routledge Handbook of Discourse Analysis. New York: Routledge, 2003, P. 79-89.

. Transmedia Traversals: Marketing Meaning and Identity. In A. Baldry y E. Montagna (Eds.), Interdisciplinary Perspectives on Multimodality: Theory and Practice. Proceedings of the Third International Conference on Multimodality. Campobasso: Palladino, 2009a, p.576-596.

Multimodality, Identity, and Time. In C. Jewitt (Ed.), Routledge Handbook of Multimodal Analysis. London-New York: Routledge, 2009b, p.140-150.

. Travels in Hypermodality. Visual Communication, 2003. vol.1 (3), 299-325.

. Discursive Technologies and the Social Organization of Meaning. Folia Linguistica, 2001, 35 (1-2), p.79-96.

MONTECINO, L. ¿Por qué marchan los estudiantes en Chile?: Discurso electrónico y poder en un ciberperiódico. Cadernos de Linguagem e Sociedade,2011. vol.12 (2), 179-209.

MONTECINO, S. Palabra dicha. Escritos sobre género, identidades y mestizaje. Santiago: Facultad de Ciencias Sociales, Universidad de Chile, 1997.

PARDO, N. Discurso en la Web: Pobreza en Youtube. Bogotá: Centro Editorial Facultad de Ciencias Humanas, Universidad Nacional de Colombia, 2012.

PÉREZ, C. (en prensa). La representación visual del movimiento estudiantil chileno en la prensa establecida y alternativa nacional: Un análisis multimodal. Revista Austral de Ciencias Sociales, (30).

. The Chilean student movement and the media: A comparative analysis on the linguistic representation of the 04 August, 2011 manifestation in right-wing and left-wing newspapers. LOGOS. Revista de Lingüística, Filosofía y Literatura,2012. vol.22 (2), 4-26.

PUJAL, M. Mujer, relaciones de género y discurso. Aprendizaje, Revista de Psicología Social. 1993, vol.8 (2), P. 201-2015.

PRECIADO, B. Manifiesto contra-sexual. Madrid: Opera Prima. p.2002. 
SCHNAITH, N. Lo visible y lo invisible en la imagen fotográfica. Madrid: La Oficina, 2011.

SERRANO, H., ZARZA, M. P., SERRANO, C., GÓMEZ, B. y IDUARTE, J. Códigos visuales de género y configuraciones sexuales evidenciadas en la fotografía. Revista Latinoamericana de Ciencias Sociales, Niñez y Juventud, 2011, (9), p. 769-782.

SCOTT, J. W. Género e historia. México D.F.: Fondo de Cultura Económica-Universidad Autónoma de México, 2008.

TUBERT, S. Del sexo al género. Los equívocos de un concepto. Madrid: Cátedra, 2003.

VAN LEEUEN, T. Discourse and Practice. New Tools for Critical Discourse Analysis. Oxford: Oxford University Press, 2008.

WODAK, R. Gender and Language: Cultural Concerns. In J. D. Wright (Ed.), International Encyclopedia of the Social \& Behavioral Sciences. 2015, Vol 9. (pp. 698-793). Oxford: Elsevier. 